\title{
Probabilistic performance assessment of low-ductility RC frames retrofitted with dissipative braces
}

\author{
F. Freddi ${ }^{1}$, E. Tubaldi ${ }^{2}$, L. Ragni ${ }^{1}$, and A. Dall'Asta ${ }^{2}$ \\ ${ }^{1}$ Department of Civil and Building Engineering and Architecture, Marche Polytechnic University, Ancona, Italy. \\ ${ }^{2}$ School of Architecture and Design, University of Camerino, Ascoli Piceno, Italy.
}

\section{SUMMARY}

The paper illustrates a probabilistic methodology for assessing the vulnerability of existing reinforced concrete (RC) buildings with limited ductility capacity retrofitted by means of dissipative braces. The aim is to highlight the most important parameters controlling the capacity of these coupled systems and specific aspects concerning the response uncertainties. The proposed methodology is based on the use of local engineering demand parameters for monitoring the seismic response and on the development of component and system fragility curves before and after the retrofit. In the first part of the paper the methodology is illustrated by highlighting its advantages with respect the existing approaches. Then, its capability and effectiveness are tested by considering a benchmark 2-dimensional RC frame designed for gravity-loads only. The frame is retrofitted by introducing elasto-plastic dissipative braces designed for different levels of base shear capacity. The obtained results show the effectiveness of the methodology in describing the changes in the response and in the failure modalities before and after the retrofit, for different retrofit levels. Moreover, the retrofit effectiveness is evaluated by introducing proper synthetic parameters describing the fragility curves and by stressing the importance of employing local EDPs rather than global EDPs in the seismic risk evaluation of coupled systems consisting in low-ductility RC frames and dissipative braces.

\section{Keywords}

Reinforced concrete frames, seismic vulnerability, fragility curves, seismic retrofit, buckling-restrained braces, probabilistic methodology.

\section{INTRODUCTION}

The damage occurred during recent earthquakes in many existing reinforced concrete (RC) buildings designed before the introduction of modern anti-seismic codes has shown that these structures are very vulnerable to the seismic action due to their reduced ductility capacity. Thus, there is a significant need of modern retrofit techniques for increasing their safety and of reliable tools for assessing the effectiveness of the retrofit.

Among the various techniques currently employed for the retrofit, the use of dissipative braces appear to be very promising [1,2]. These braces provide a supplemental path for the earthquake induced horizontal actions and thus enhance the seismic behaviour of the frame by adding dissipation capacity and, in some cases, stiffness to the bare frame. It should be noted, however, that the introduction of a bracing system into a low-ductility frame often induces remarkable changes both in the collapse modalities and in the probabilistic properties of the seismic response of the structure. The latter aspect assumes a considerable importance in consequence of the high degree of uncertainty affecting the seismic input and of the 
differences in the propagation of this uncertainty through the two resisting systems (RC frame and dissipative bracing). For these reasons, the evaluation of the effectiveness of this type of retrofit technique in reducing the frame vulnerability should be performed within a probabilistic framework.

An increasingly popular approach for assessing in probabilistic terms the seismic vulnerability of structural systems and the effectiveness of a retrofit technique involves the development of fragility curves. These tools provide the probability of exceeding a specified limit state or failure condition, conditional to the strong-motion shaking severity, quantified by means of an appropriately selected intensity measure (IM). In this context, fragility curves are employed by [3] to investigate the effectiveness of retrofit techniques, such as addition of shear walls, column jacketing, and confinement of column plastic hinge regions by using externally bonded steel plates. In [4], the authors also assess the effect of column strengthening on the seismic vulnerability of RC frames designed for gravity loads only by comparing the fragility curves of a benchmark building before and after retrofit. However, only few works analyze the impact of the use of braces on the fragility of existing RC frames. Among these, in [5] the case of viscous dampers is considered, while in [6] and [7] the cases of elastic steel eccentric braces and buckling restrained braces are illustrated respectively. Although in these studies probabilistic methodologies are employed for evaluating the effectiveness of different retrofit schemes, some modifications and extensions should be introduced in order to properly address the specific issues deriving from the use of dissipative braces for the retrofit of existing low-ductility RC frames.

The first issue is related to the choice of appropriate engineering demand parameters (EDPs) for monitoring the seismic response and evaluating the performance of the frame and of the retrofit system. In the studies listed above the fragility curves are developed by using the peak interstorey drift as unique global EDP. This strategy is commonly pursued since monitoring the time-history of the local response of all structural members may be cumbersome, especially when complex models with a high number of degrees of freedoms are considered. The system capacity is defined in the studies cited above based on one of the two approaches: i) by employing the interstorey drift limits suggested in seismic codes, such as in $[3,4]$, or ii) by deriving the interstorey drift limits from the member-level limits suggested in seismic codes (i.e., plastic rotation capacity of members) through a simplified analysis, such as pushover analysis [3-7]. Obviously, in both the cases, the capacity limits must be updated properly to account for the retrofit, as done in $[3,4]$. The first of the two approaches described above is suitable if well-established relationships between local failures and global EDPs are available. This is the case of new ductile structures designed by following modern antiseismic rules such as strength hierarchy (capacity design) and provided with proper seismic detailing. On the other hand, in existing structures designed before the introduction of modern anti-seismic codes, the relationships between local failure and global EDPs may change case by case, as demonstrated by the very different drift limits present in the literature $[3,4]$. Moreover, in existing structures retrofitted by means of dissipative braces, these relationships could change by increasing the dimension of the braces, due to the reduction of the flexural ductility capacity of the compressed columns involved in the bracing system. For these reasons, the use of global EDPs with code-specified limits is not recommended for the assessment of existing RC frames. The second approach, involving the use of pushover analysis to relate local and global EDPs, though more accurate than the first, inherits the limits of accuracy affecting the pushover analysis. Therefore, it cannot be applied in some 
cases, e.g., when dissipative braces with viscous behaviour are used, or when the vulnerability of the retrofit system is affected by low cycle fatigue issues.

By contrast, the use of local component-specific EDPs [8-11], such as the strain demand at the most critical element sections or the shear demand on a beam-column joint, though more cumbersome, is not affected by any of the above mentioned limitations. In addition, it permits to appropriately assess the probabilistic response of single resisting components (including the braces), their contribution to the system vulnerability, and the impact of the retrofit on the local response of the individual members [12]. This aspect may be also crucial for the estimation of the direct losses due to seismic damage, since it is easier to associate a cost to the damage of the single component (beam, column, brace) rather than to the system $[13,14]$.

A second relevant issue in defining a probabilistic methodology of analysis concerns the evaluation of the retrofit technique effectiveness, which is accomplished in the studies cited above by comparing the median values of the fragility curves of the structure before and after retrofit. This comparison has often implied the use of structural-independent $I M \mathrm{~s}$ in past studies, such as the not very efficient peak ground acceleration (PGA) [3-7]. In fact, when the natural period of the bare frame differs from the natural period of the retrofitted frame, the comparison between fragility curves obtained by using more efficient structure-specific IMs [15] (e.g., the spectral acceleration at the fundamental period of the structure) would not directly provide information about the effectiveness of the retrofit [16]. Furthermore, a more rational approach to accurately compute the changes in the safety margin due to retrofit should also account for the dispersion of the fragility curve, since this parameter affects the estimate of the seismic risk $[11,17]$.

This paper proposes a fragility-based methodology aiming at overcoming the limits of the studies mentioned above. The methodology is developed by combining existing techniques already employed for different structural systems and by tailoring these techniques to the specific problem analyzed. Local EDPs are used to develop single component fragility curves while system fragility curves are derived and described by proper synthetic parameters suitable for use with any $I M$.

In the first part of the paper, the proposed methodology is accurately illustrated by stressing its advantages with respect to existing approaches. Then, its capability and effectiveness is tested by considering a realistic benchmark RC frame with limited ductility capacity. The frame is retrofitted by inserting a system of buckling-restrained braces (BRBs) with elastoplastic behaviour designed for several levels of the base shear capacity. The braces are designed by applying a widespread method based on an equivalent single degree of freedom (SDOF) approximation [1,18]. The application of the probabilistic methodology permits to evaluate the accuracy of the simplified design criterion and also to draw some important considerations about the behaviour of the single resisting components, the effectiveness of the retrofit technique, and the structural safety increment.

\section{PROBABILISTIC METHODOLOGY FOR VULNERABILITY ASSESSMENT}

The seismic response of the frame before and after retrofit is affected by uncertainties in the earthquake input (record-to-record variability), in the properties defining the system (model parameter uncertainty), and by lack of knowledge (epistemic uncertainty). The uncertainty affecting the earthquake input is taken into account in the methodology by selecting a set of natural ground motion (g.m.) records that reflect the variability in duration, frequency content, and other characteristics of the input expected to act on the system. The effects of 
model parameter uncertainty and epistemic uncertainty are usually less notable than the effects of record-to-record variability and they are not considered in this study $[11,19]$.

In order to generate fragility curves, multi-record incremental dynamic analysis (IDA) [20] is performed by subjecting the system to a set of selected g.m. records for increasing values of the seismic intensity measure (IM). The methodology proposed in this study is oriented to the use of structural-dependent IMs. In particular, the spectral acceleration $S_{a}(T)$ at the fundamental period of the structure $T$ for a damping factor $\xi=5 \%$ [15] is employed as $I M$ due to its efficiency. This choice requires scaling the g.m. records in order to obtain the same value of $S_{a}(T)$ for the natural period of the structure, which is different for the bare and the retrofitted frames. Advantages and drawbacks of the different g.m. selection and scaling techniques available in the literature may be found in [15,21].

Multi-record IDA provides a set of samples of appropriately selected EDPs monitoring the system response for discrete values of the $I M$. As already discussed in the introduction, local EDPs, directly related to the component failure modes, are used in order to monitor the behaviour of the most vulnerable system components and to capture the modifications to the frame response and collapse modalities induced by the introduction of the bracing system. The seismic demand on the frame elements (beams and columns) due to flexural moments and axial forces is controlled by monitoring the maximum-over-time values of the concrete compressive strain $\varepsilon_{c}$ and of the steel strain $\varepsilon_{s}$ at the most critical sections. The non-ductile mechanisms of the frames are controlled by recording the maximum-over-time values of the shear force $V$ at the critical sections of each element of the frame, the diagonal tension stress $\sigma_{t}$, and the diagonal compression stress $\sigma_{c}$ at each beam-column joint. Finally, in the retrofitted case, the seismic demand imposed on the retrofit system is controlled by evaluating the maximum-over-time value of a damage parameter $i_{d}$ (e.g., the maximum-overtime value of the ductility demand $\mu_{d}$ for elasto-plastic braces) for each dissipative brace.

The component fragility curves for the bare and the retrofitted frame are evaluated by considering the following limit states (LSs) chosen coherently with the monitored EDPs: LS1) $\varepsilon_{c}$ exceeding the capacity limit $\varepsilon_{c u}$ at each critical section, LS2) $\varepsilon_{s}$ exceeding the capacity limit $\varepsilon_{s u}$ at each critical section, LS3) the shear demand $V$ exceeding the shear resistance $V_{u}$ at each critical section, LS4) $\sigma_{c}$ exceeding the resistance in compression $\sigma_{c u}$ at each joint, LS5) $\sigma_{t}$ exceeding the resistance in tension $\sigma_{t u}$ at each joint, and LS6) the damage index $i_{d}$ overcoming the corresponding capacity $i_{d u}$ at each dissipative brace, (e.g., $\mu_{d}$ overcoming the limit $\mu_{d u}$ for elasto-plastic braces). The considered EDPs and the corresponding LSs are summarized in Table 1.

The system fragility curves are then derived by assuming a series arrangement of the components, i.e., failure in one component yields system failure. The choice of the LSs and the series arrangement assumption made in this paper is consistent with seismic code prescriptions requiring that all the considered LSs must be verified for all the structural members. Moreover, the series arrangement is coherent with the objective of limiting structural damage on the existing frame, often sought by the retrofit criteria. However, it is noteworthy that the proposed methodology can be applied also when different assumptions are made to obtain the system fragility curves. Finally, it is noted that the proposed methodology is purely numerical since it is based on the direct comparison between the samples of the EDPs and the corresponding capacity limits. Thus, the correlation among the various component LSs, which affects the estimate of the system vulnerability [12], is automatically taken into account [3]. 
Table 1. Limit states

\begin{tabular}{ccc}
\hline EDPs & Capacity limits & LSs \\
\hline \multicolumn{3}{c}{ Combined flexural and axial behaviour } \\
\hline$\varepsilon_{c}$ & $\varepsilon_{c u}$ & LS1: concrete failure of frame elements \\
$\varepsilon_{s}$ & $\varepsilon_{s u}$ & LS2: steel failure of frame elements \\
\hline & & Brittle behaviour \\
\hline$V$ & $V_{u}$ & LS3: shear failure of frame elements \\
$\sigma_{c}$ & $\sigma_{c u}$ & LS4: compression failure of frame joints \\
$\sigma_{t}$ & $\sigma_{t u}$ & LS5: tension failure of frame joints \\
\hline & & Braces behaviour \\
\hline$i_{d}$ & $i_{d u}$ & LS6: failure of dissipative braces \\
\hline
\end{tabular}

In this paper, the numerical fragility curves are approximated by analytical lognormal curves obtained through least-square minimization. The assumption of lognormality simplifies the analysis of the results and permits to synthetically describe the fragility of the systems considered by means of the two characteristic parameters describing the lognormal distribution. These two parameters are the median fragility capacity, $I M_{c, 50}$, defined as the $50^{\text {th }}$ fractile of the lognormal fragility curve (i.e., the $I M$ corresponding to $50 \%$ probability of exceeding the system capacity), and the logarithmic standard deviation or dispersion measure, $\beta_{c}$, given by:

$$
\beta_{c}=\frac{1}{2} \ln \left(\frac{I M_{c, 84}}{I M_{c, 16}}\right)
$$

where $I M_{c, 84}$ and $I M_{c, 16}$ are the $I M$ values corresponding respectively to the $84^{\text {th }}$ and the $16^{\text {th }}$ fractile of the lognormal fragility curve, i.e., the values of the $I M$ which yield failure respectively in 84 and 16 cases over 100. The use of lognormal fragility curves is very common and widely accepted in performance based earthquake engineering, since it permits to estimate the above defined parameters even when a limited number of EDP samples are available. Moreover, it permits to easily incorporate the effects of other sources of uncertainty in addition to the record-to-record variability, and it simplifies the evaluation of the seismic risk [22].

As already pointed out in the introduction, if a structural-dependent $I M$ such as $S_{a}(T)$ is employed to monitor the seismic intensity, the comparison of the values of $I M_{c, 50}$ obtained for the bare and retrofitted frame would not directly provide information about the effectiveness of the retrofit, since the natural period changes due to the retrofit. For this reason, the comparison should be performed between the values of the "capacity margin ratio" $m_{50}$ [15], defined as the ratio between the value of $I M_{c, 50}$ and the value of the $I M$ corresponding to a reference return period, $I M_{T R}$ (e.g., 2475 years in [16]). In the proposed methodology, $I M_{T R}$ is assumed as the value of $S_{a}(T)$ for a reference return period such that $m_{50}=1$ for the bare frame, as illustrated in Figure 1. By this way, the value of $m_{50}$ obtained for the retrofitted frame directly measures the increment of seismic intensity that can be withstood by the retrofitted structure. In a similar way, based on the ratio $I M_{c, 84} / I M_{T R}$ and $I M_{c, 16} / I M_{T R}$, the factors $m_{84}$ and $m_{16}$ corresponding to the $84^{\text {th }}$ and $16^{\text {th }}$ fractiles of increment of capacity are defined. These parameters, together with parameter $\beta_{c}$, may also be used to assess in probabilistic terms the effectiveness of the retrofit, by accounting for the dispersion of the system response, which may have a non-negligible influence on the seismic risk assessment $[11,17]$. 


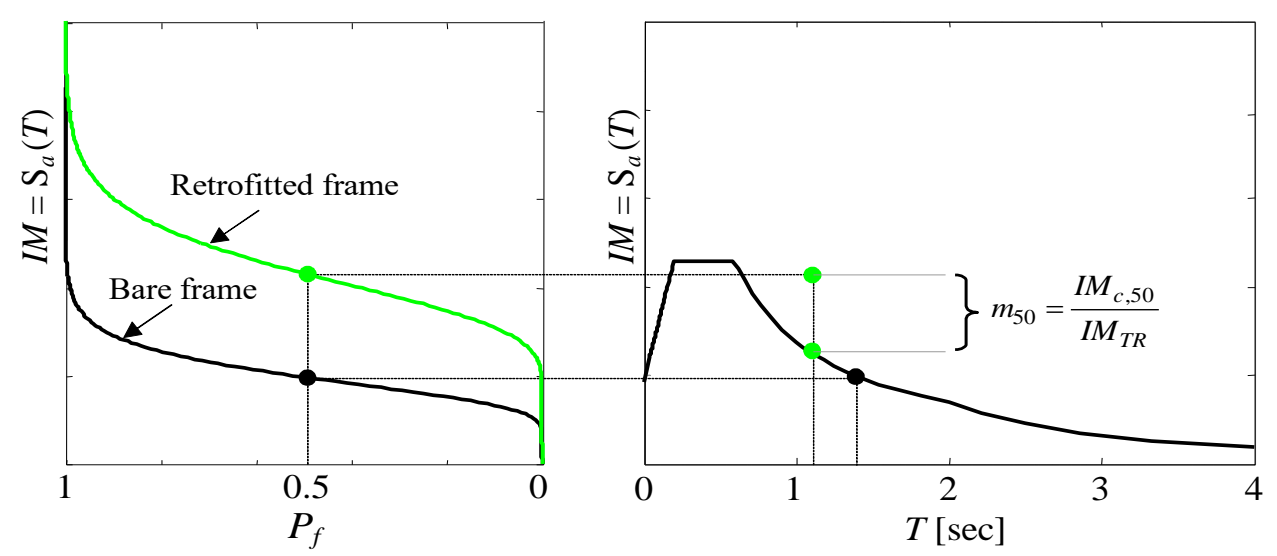

Figure 1 . Definition of capacity margin ratio $m_{50}$ : seismic fragility curves before and after retrofit (left), uniform hazard spectrum such that $m_{50}=1$ for the bare frame (right).

Finally, it should be noted that the proposed methodology permits to draw some important considerations regarding the performance of the system before and after the retrofit. In fact, by directly comparing the single component fragility curves to each other and to the system fragility curve, it is possible to evaluate the most vulnerable components and their contribution to the system vulnerability. This comparison permits to understand the changes in the response and in the failure modalities of the frame due to the retrofit.

\section{CASE STUDY}

A three storey ordinary $\mathrm{RC}$ moment resisting frame, already used as case study by other authors [19,23], is considered to apply the proposed methodology and demonstrate its capability. This case study has been chosen because an extended experimental campaign has been carried out on 1:3 reduced scale models of the frame and of its subassemblages [24-26]. Thus, the detailed information available regarding the global frame's [26] and the local members' behaviour [25] permits an accurate validation of the finite element model not only at a global, but also at a local scale. This is important, since the proposed methodology involves local EDPs monitoring.

Figure 2 shows the general layout of the structure while Figure 3 illustrates some beam reinforcement detailing (complete detailing may be found in [24]).

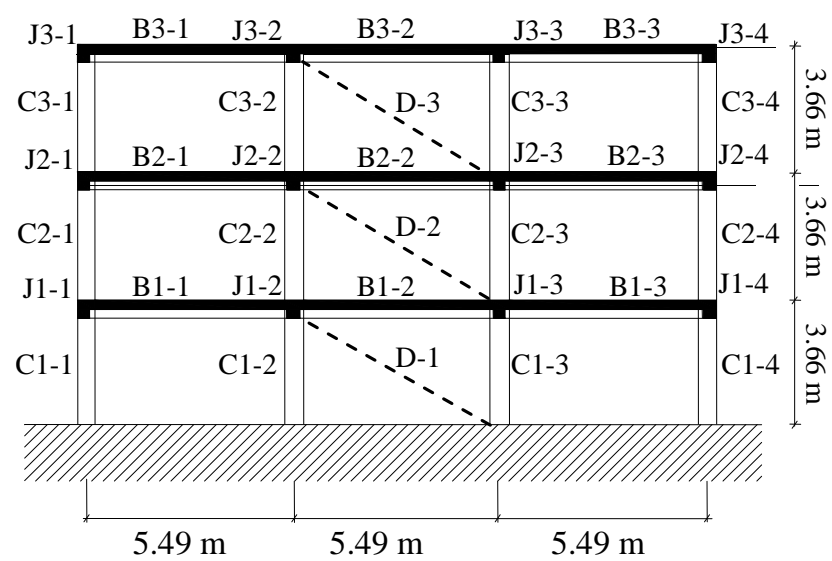

Figure 2. General layout of the structure and braces arrangement (adapted from [24]). 


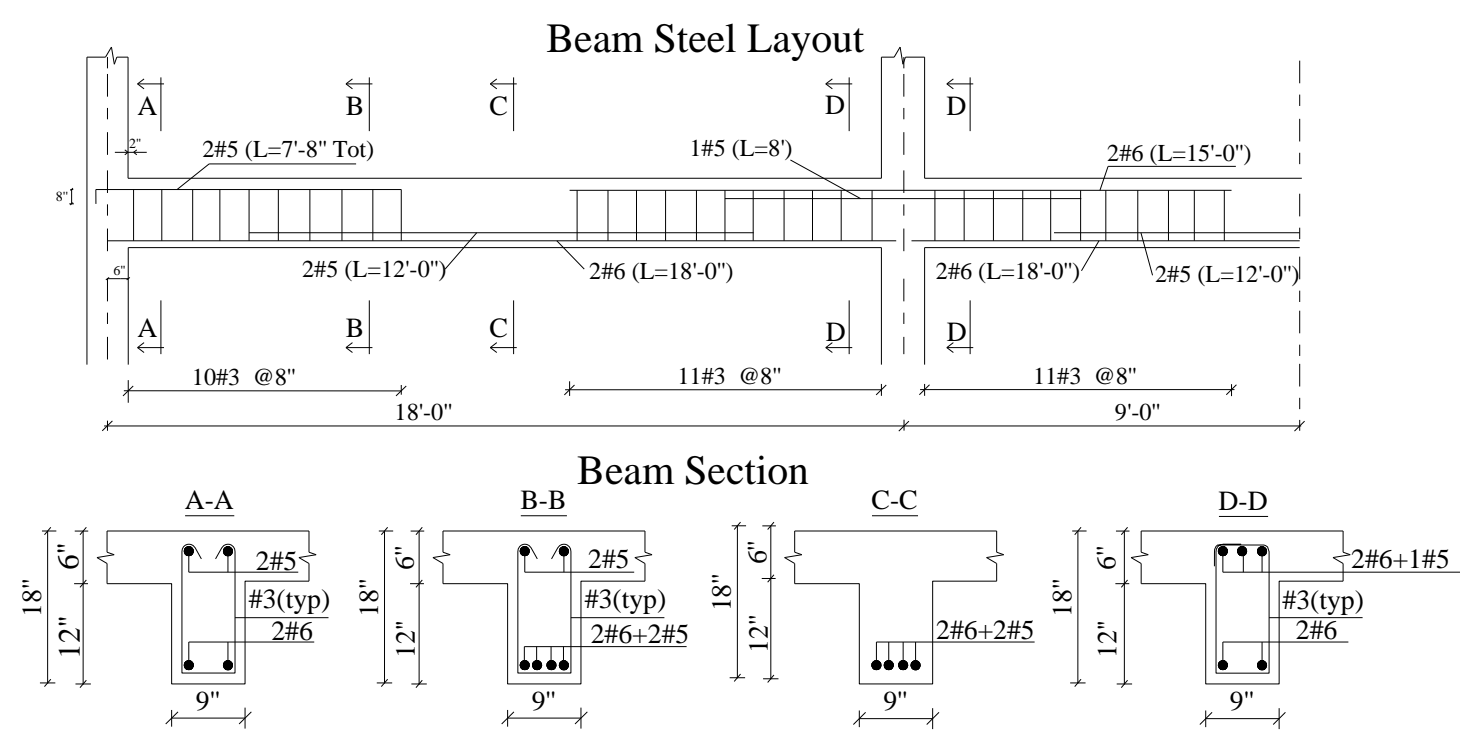

Figure 3. Beam reinforcement detailing (adapted from [24]).

The building has been designed for gravity loads only and without any seismic detailing, by applying the design rules existing before the introduction of modern anti-seismic codes. The considered building frame consists of three stories $3.66 \mathrm{~m}$ high, for a total height of $11 \mathrm{~m}$, and of three bays, each $5.49 \mathrm{~m}$ wide. Columns have a $300 \times 300 \mathrm{~mm}^{2}$ square section while beams are $230 \times 460 \mathrm{~mm}^{2}$ at each floor. Grade 40 steel $\left(f_{y}=276 \mathrm{MPa}\right)$ and concrete with compression resistance $f_{c}{ }^{\prime}=24 \mathrm{MPa}$ were employed in the design, following the provision of ACI 318-89 code [27]. Since earthquake loads were neglected and wind induced forces on such a low-rise structure were relatively small, no lateral load was considered for the design.

A two dimensional finite element (FE) model of the structure is developed in OpenSees [28]. The "beam with hinges" element [29] is employed to describe the nonlinear hysteretic response of beams and columns. In the plastic hinge zone, the behaviour of concrete is described by the non linear degrading Concrete 02 material model [28]. The behaviour of steel reinforcements is described by the Hysteretic material model [28], whose parameters controlling pinching, damage and degraded unloading stiffness are calibrated to obtain the best fit between the numerical and the experimental results. The plastic hinge length for beams and columns is evaluated based on the formula proposed in [30]:

$$
L_{p}=0.12 L_{V}+0.014 \alpha d_{b l} f_{y}
$$

where $L_{V}$ is the element shear length, $\alpha$ is a parameter which assumes the value 0 (or 1 ) in presence (absence) of lap-spliced rebars at the element's end sections, $d_{b l}$ is the longitudinal bar diameter and $f_{y}$ is the steel yield strength. In order to account for concrete cracking, the elastic part of each element is modelled with an effective flexural stiffness, evaluated by means of moment-curvature analysis, for the axial force level induced by the dead loads.

The developed FE model is validated by comparing the available experimental results with the simulated test results of the 1:3 scale numerical FE models of the frame and of its subassemblages. The material properties in the scaled models are defined coherently with the results of the experimental test performed on the materials specimens. In [25], the authors report the results concerning four 1:3 scale column specimens with and without lap splices loaded with low and high levels of axial forces, representing respectively the interior and 
exterior column at floor slab and at beam soffit levels. The study also reports the results of the tests performed on two 1:3 scale specimens of an exterior and an interior beam-column joint subassemblage. Both the columns and the joints were subjected to reverse cyclic loading for increasing drift amplitudes up to failure. Figures 4 and 5 show the comparisons between the experimental and the numerical results. The simulated test results show a satisfactory agreement with the experimental results and demonstrate the capability of the FE model to simulate the cyclic local members behaviour.

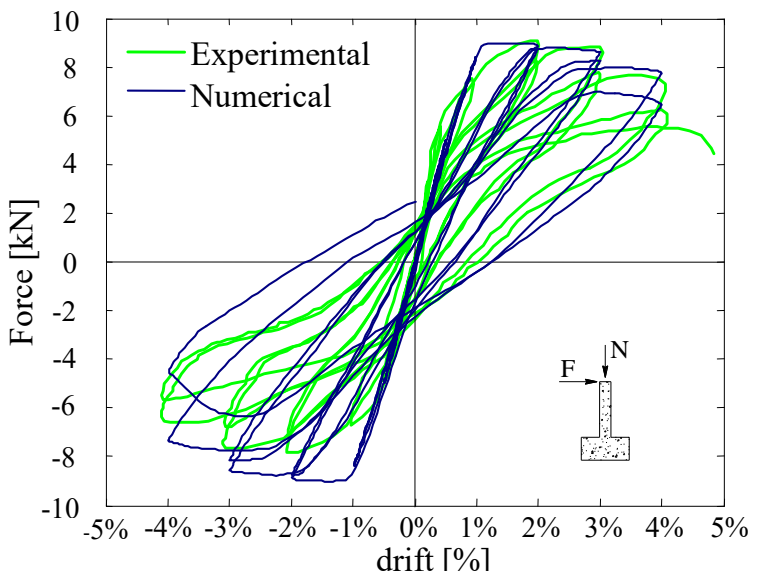

(a)

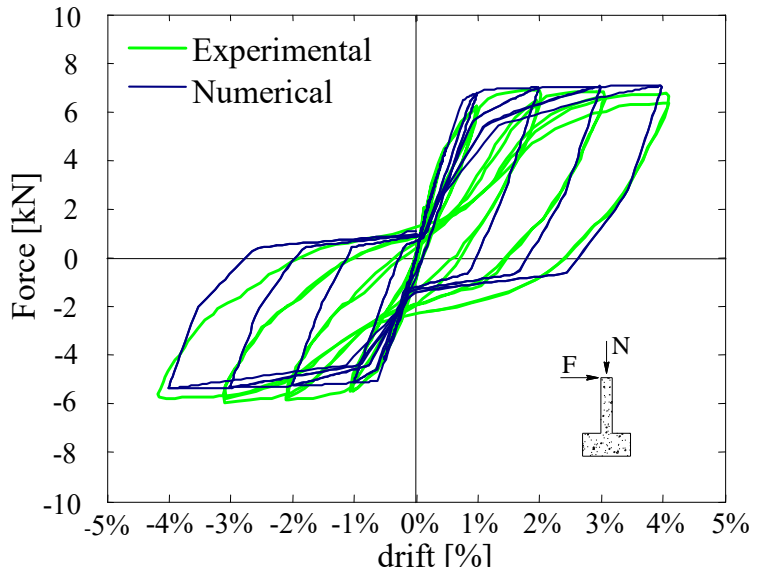

(b)

Figure 4. Experimental and numerical lateral load-drift comparison for column specimen a) with lap splices and high axial load and b) without lap splices and low axial load.

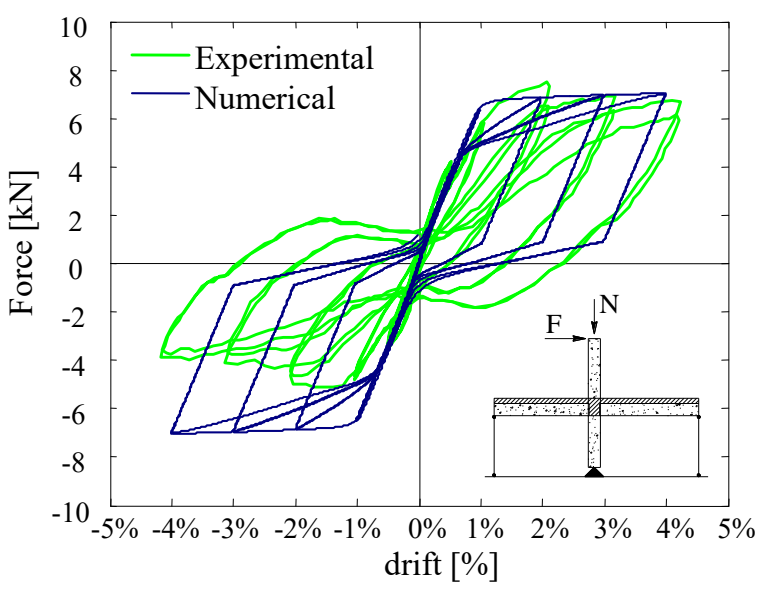

(a)

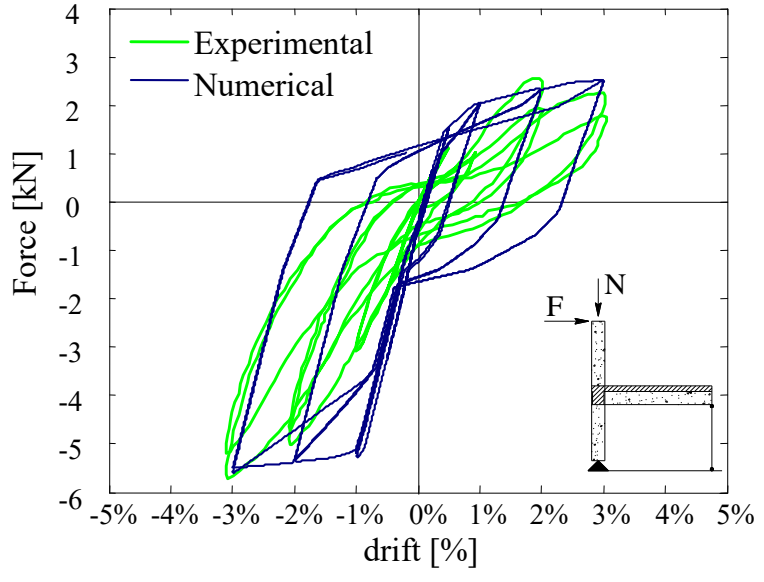

(b)

Figure 5. Experimental and numerical lateral load-drift comparison for interior slab-beamcolumn subassemblage at a) interior node, and b) exterior node.

In [26], the results of the experimental tests carried on the 1:3 scale frame are reported. The results of snap back and white noise tests provide information about the frame vibration periods and the modal shapes. The first three natural periods measured in the experimental test results $(0.538,0.177$ and $0.119 \mathrm{sec})$ are in close agreement with the periods provided by the 1:3 scale FE model with uncracked gross stiffness properties $(0.561,0.180$, and 0.110 sec). A good agreement is also observed in the first three modal shapes.

Shaking table tests results are also available, describing the time-history of the frame 
response under the Kern County 1952, Taft Lincoln School Station, N021E component record scaled for different levels of the seismic intensity (PGA $=0.05 \mathrm{~g}, 0.20 \mathrm{~g}$ and $0.30 \mathrm{~g}$ ). Figure 6 shows the comparison between the top storey displacements of the 1:3 scale experimental and numerical models for the various levels of the seismic intensity. In the FE model, damping sources other than the hysteretic dissipation of energy are modelled through the Rayleigh damping matrix. The values of the mass-related and stiffness-related damping coefficients are such that the best fit to the numerical results is achieved and yield a damping factor of $3 \%$ for the first two vibration modes. The agreement between the simulated and experimental response history is very satisfactory for values of the PGA equal to $0.05 \mathrm{~g}$ and $0.02 \mathrm{~g}$, while for PGA $=0.03 \mathrm{~g}$ the agreement is not as good, although the peak response values are simulated with good accuracy.
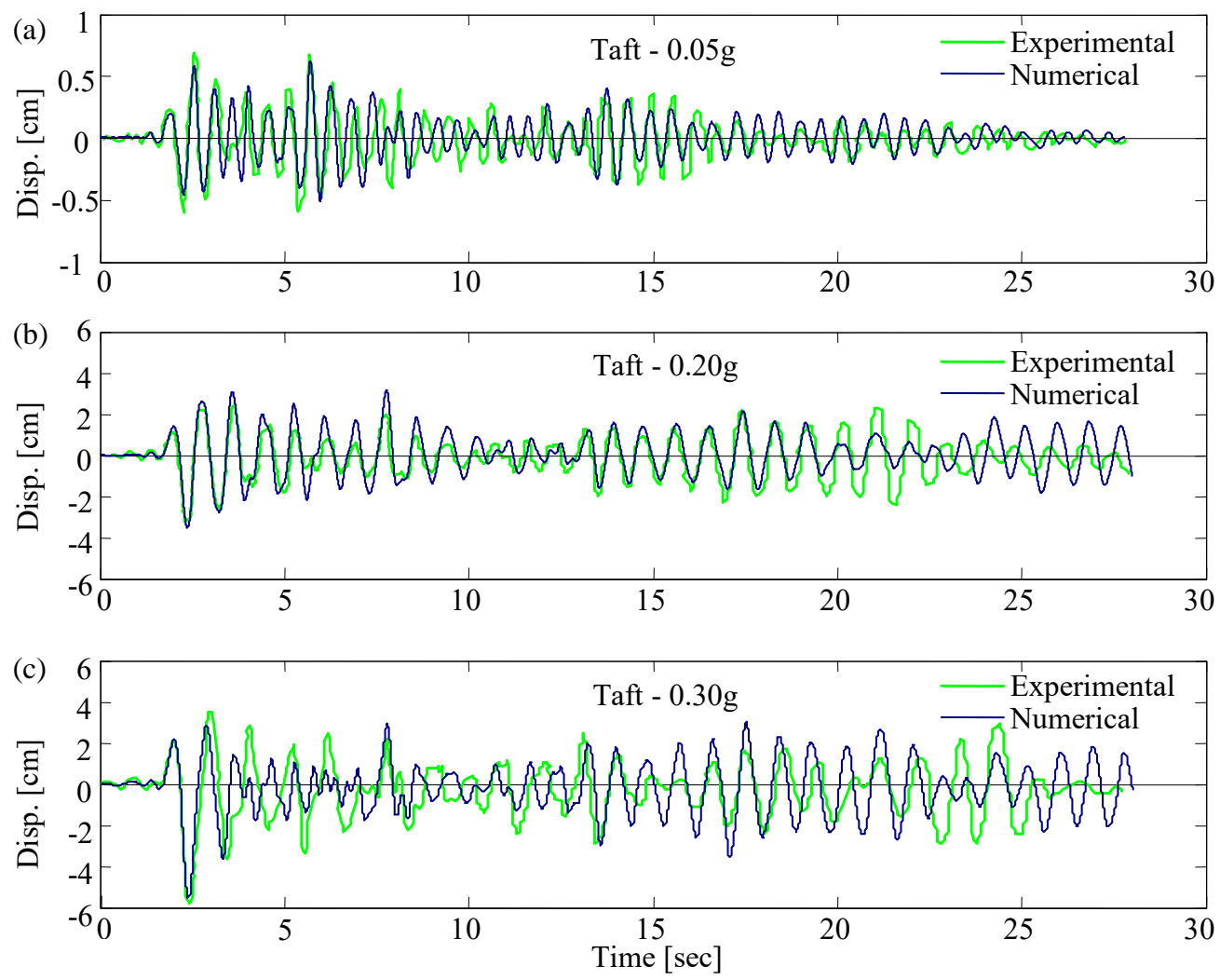

Figure 6. Comparison of numerical and experimental shaking table tests results: top storey displacement for a) $\mathrm{PGA}=0.05 \mathrm{~g}, \mathrm{~b}) \mathrm{PGA}=0.20 \mathrm{~g}$, and c) $\mathrm{PGA}=0.30 \mathrm{~g}$.

\section{RETROFITTING OF RC FRAME WITH ELASTO-PLASTIC BRACES}

\subsection{Retrofit design method}

This paragraph synthetically illustrates the procedure employed for the design of the dissipative braces with elasto-plastic behaviour employed for the retrofit. The procedure is based on an equivalent SDOF system approximation $[1,18,31,32]$. In particular, an equivalent non linear SDOF system is defined to account for the non linear behaviour of the bare frame [31,32]. The dissipative braces considered in this paper are made by an elasto-plastic dissipation device placed in series with an elastic brace exhibiting adequate over-strength. The properties of the dissipative brace are defined based on the properties of its components 
[33]. If $K_{b}$ denotes the axial stiffness of the elastic brace and $K_{0}, F_{0}$ and $\mu_{0 u}$ respectively the stiffness, yielding force and ductility capacity of the elasto-plastic device, the dissipative brace stiffness $K_{d}$ and ductility capacity $\mu_{d u}$ are given by:

$$
K_{d}=\frac{K_{b} K_{0}}{K_{b}+K_{0}} \quad, \quad \mu_{d u}=\frac{K_{0}+K_{b} \mu_{0 u}}{K_{b}+K_{0}}
$$

while the dissipative brace yielding force $F_{d}$ is equal to $F_{0}$. Usually, the value of $\mu_{0 u}$ is given by the dissipation device manufacturer, while the brace ductility $\mu_{d u}$ depends on the ratio $K_{0} / K_{b}$ and is a design parameter. It should be observed that large values of the ductility ratio $\mu_{d u} / \mu_{0 u}$ lead to very onerous metallic brace dimensions, whereas low values of $\mu_{d u} / \mu_{0 u}$ lead to small brace dimensions and consequently to brace buckling problems.

The method followed to design the dissipative system is based on pushover analysis of the existing frame under a distribution of forces corresponding to its first vibration mode. The structure is pushed up to an ultimate displacement $d_{u}$ corresponding to the design damage level. The corresponding value of the base shear is denoted as $V_{f}^{1}$. The dissipative bracing system is assumed to behave as an elastic-perfectly plastic system, with base shear capacity equal to $V_{d}^{1}$, ductility capacity equal to $\mu_{d u}$ and with the same ultimate displacement of the bare frame. This last assumption aims at obtaining a simultaneous failure of both the frame and the dissipative braces. It is noteworthy that the value of $V_{d}^{1}$ is a design choice and depends on the objective of the retrofit. For a given value of $V_{d}^{1}$, the stiffness of the bracing system at the first storey is given by:

$$
K_{d}^{1}=\frac{V_{d}^{1} \mu_{d u}}{d_{u} \delta^{1}}
$$

where $\delta^{l}$ is the interstorey drift at the first storey, normalized with respect to the top floor displacement according to the first modal shape. The shear $V_{d}^{i}$ and stiffness $K_{d}^{i}$ of the dissipating bracing system at each storey are determined by the following relations:

$$
V_{d}^{i}=V_{d}^{1} v^{i}, K_{d}^{i}=K_{d}^{1} k^{i}
$$

where $v^{\mathrm{i}}$ and $k^{\mathrm{i}}$ are the shear force and stiffness at each storey, normalized with respect to the base shear and base stiffness according to the first mode of the bare frame. The stiffness distribution adopted for the dissipative braces at each storey ensures that the first modal shape of the bare frame remains unvaried after the retrofit. This avoids drastic changes to the internal action distribution in the frame, at least in the range of the elastic behaviour. Additionally, the chosen strength distribution of the dissipative braces aims at obtaining simultaneous yielding of the devices at all the stories and, thus, a global ductility of the bracing system coinciding with the ductility of the single braces. Given $V_{d}^{i}$ and $K_{d}^{i}$, the braces properties $\left(K_{0}^{i}, F_{0}^{i}\right.$ and $K_{b}^{i}$ ) at each storey can be determined based on the number of braces and on geometrical considerations, and by applying Equation (3).

\subsection{Application of the design method to the case study}

Figure 7a shows the pushover curve obtained for the load distribution relative to the first 
vibration mode of the bare frame (mass participation factor of $86.4 \%$ ). The ultimate capacity of the frame members is evaluated by considering the strain demand in the most critical concrete and steel fibres $\left(\varepsilon_{c}\right.$ and $\left.\varepsilon_{s}\right)$ and the corresponding limits $\varepsilon_{c u}=0.0035$ and $\varepsilon_{s u}=0.04$ [34]. The other EDPs and failure modes reported in Table 1 are not monitored in the application of the simplified design procedure. The top storey displacement $d=0.102 \mathrm{~m}$ denoting the failure of the most critical element (columns C1-2 of Figure 2) is posed in evidence in Figure 7a. It corresponds to a maximum interstorey drift of about $1.0 \%$, and to a base shear capacity $V_{f}^{i}=186 \mathrm{kN}$ and it is assumed as the ultimate displacement $d_{u}$ in the design procedure application. The yielded and failed sections at this displacement level are reported in Figure 7b. Obviously, after this first failure, the bare frame still possesses a residual capacity and can be pushed up to a top storey displacement $d=0.183 \mathrm{~m}$, at which all the base storey columns fail (Figure 7c). It is worth to notice that the damage distribution illustrated in Figure $7 \mathrm{c}$ is very similar to the damage layout experimentally observed under severe shaking and reported in [26].

The dissipative devices adopted for the retrofit of the case study are buckling-restrained braces (BRBs). Differently from the BRBs commonly used in steel-structures, the dissipative devices employed here and generally used for retrofitting low-ductility RC frames are quite short, in order to obtain low yield displacements. Thus, the dissipative diagonal brace is made by assembling the BRB in series with an elastic brace characterized by an adequate overstrength and stiffness. An example of these dissipative braces may be found in [35]. Usually, the ductility capacity $\mu_{0 u}$ of the BRBs spans in the range 15-20 [35]. In this application, $\mu_{0 u}$ is assumed equal to 15 , while the ductility capacity of the whole brace $\mu_{d u}$ is assumed equal to 12 in order to obtain adequate dimension of the elastic braces. The behaviour of BRBs can be described by an elasto-plastic constitutive law [35,37]. In this study, the bi-linear material model Steel 02 [28] available in Opensees is assumed to simulate the braces behaviour.

The bare frame is retrofitted by inserting a bracing system designed for several retrofit levels, measured by the ratio $\alpha$ between the base shear capacity of the bracing system $V_{d}^{1}$ and that of the bare frame $V_{f}^{1}$. Parameter $\alpha$ assumes discrete values in the range from 0 (bare frame) to 3.2. In Figure 7a, the pushover curves of the retrofitted frame are reported and compared with the pushover curve of the bare frame.

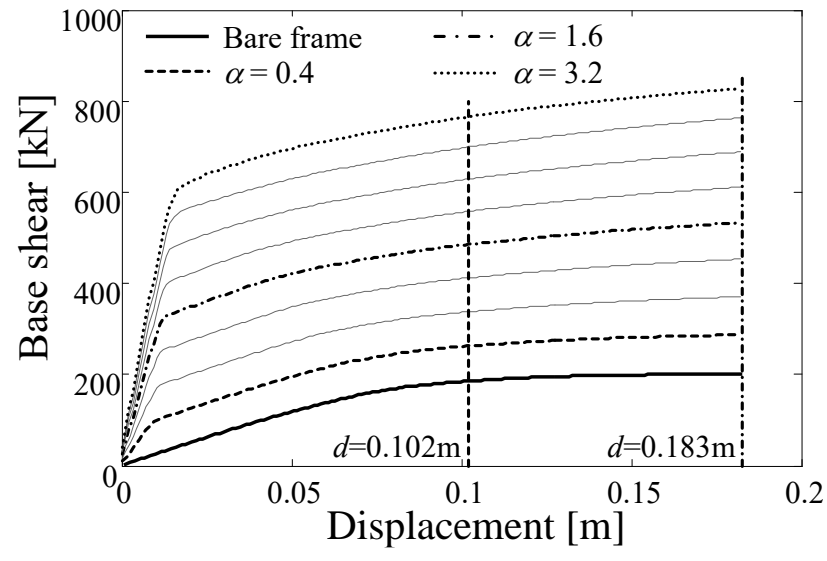

(a)

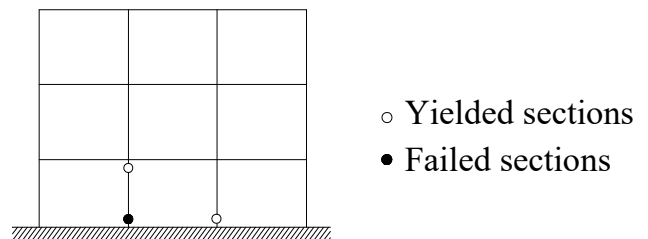

(b)

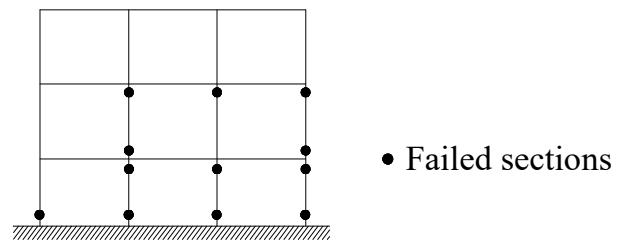

(c)

Figure 7. a) Pushover curves for bare and retrofitted frame, b) mapping of plastic hinges at $d=0.102 \mathrm{~m}$, and c) mapping of plastic hinges at $d=0.183 \mathrm{~m}$. 
In Table 2, the axial yield force $F_{d}^{i}$ and elastic stiffness $K_{d}^{i}$ of the dissipative braces are given for the different retrofit levels considered. The properties of the buckling-restrained devices $\left(K_{0}^{i}, F_{0}^{i}\right)$ and the stiffness of the elastic link braces $\left(K_{b}^{i}\right)$ at each storey are determined from the properties of the dissipative braces on the basis of the indication given in section 4.1. Table 2 also reports the fundamental vibration periods for each retrofit level considered, calculated by considering an effective stiffness of the RC frame elements.

Table 2. Dissipative braces properties at each storey

\begin{tabular}{|c|c|c|c|c|c|c|c|c|}
\hline & \multicolumn{2}{|c|}{$\alpha=0.4$} & \multicolumn{2}{|c|}{$\alpha=0.8$} & \multicolumn{2}{|c|}{$\alpha=1.2$} & \multicolumn{2}{|c|}{$\alpha=1.6$} \\
\hline$T$ & \multicolumn{2}{|c|}{$0.670 \mathrm{sec}$} & \multicolumn{2}{|c|}{$0.521 \mathrm{sec}$} & \multicolumn{2}{|c|}{$0.448 \mathrm{sec}$} & \multicolumn{2}{|c|}{$0.404 \mathrm{sec}$} \\
\hline \multirow[t]{2}{*}{ Storey } & $F_{d}^{i}$ & $K_{d}^{i}$ & $F_{d}^{i}$ & $K_{d}^{i}$ & $F_{d}^{i}$ & $K_{d}^{i}$ & $F_{d}^{i}$ & $K_{d}^{i}$ \\
\hline & {$[\mathrm{kN}]$} & {$[\mathrm{kN} / \mathrm{m}]$} & {$[\mathrm{kN}]$} & {$[\mathrm{kN} / \mathrm{m}]$} & {$[\mathrm{kN}]$} & {$[\mathrm{kN} / \mathrm{m}]$} & {$[\mathrm{kN}]$} & {$[\mathrm{kN} / \mathrm{m}]$} \\
\hline 1 & 88 & 36046 & 175 & 72091 & 263 & 108137 & 351 & 144183 \\
\hline 2 & 75 & 25106 & 150 & 50212 & 226 & 75317 & 301 & 100423 \\
\hline 3 & 43 & 22921 & 86 & 45843 & 130 & 68764 & 173 & 91685 \\
\hline & \multicolumn{2}{|c|}{$\alpha=2.0$} & \multicolumn{2}{|c|}{$\alpha=2.4$} & \multicolumn{2}{|c|}{$\alpha=2.8$} & \multicolumn{2}{|c|}{$\alpha=3.2$} \\
\hline$T$ & \multicolumn{2}{|c|}{$0.374 \mathrm{sec}$} & \multicolumn{2}{|c|}{$0.352 \mathrm{sec}$} & \multicolumn{2}{|c|}{$0.335 \mathrm{sec}$} & \multicolumn{2}{|c|}{$0.321 \mathrm{sec}$} \\
\hline \multirow[t]{2}{*}{ Storey } & $F_{d}^{i}$ & $K_{d}^{i}$ & $F_{d}^{i}$ & $K_{d}^{i}$ & $F_{d}^{i}$ & $K_{d}^{i}$ & $F_{d}^{i}$ & $K_{d}^{i}$ \\
\hline & {$[\mathrm{kN}]$} & {$[\mathrm{kN} / \mathrm{m}]$} & {$[\mathrm{kN}]$} & {$[\mathrm{kN} / \mathrm{m}]$} & {$[\mathrm{kN}]$} & {$[\mathrm{kN} / \mathrm{m}]$} & {$[\mathrm{kN}]$} & {$[\mathrm{kN} / \mathrm{m}]$} \\
\hline 1 & 438 & 180228 & 526 & 216274 & 614 & 252319 & 702 & 288365 \\
\hline 2 & 376 & 125529 & 451 & 150635 & 526 & 175741 & 601 & 200847 \\
\hline 3 & 216 & 114607 & 259 & 137528 & 302 & 160449 & 346 & 183371 \\
\hline
\end{tabular}

\section{VULNERABILITY ASSESSMENT}

For the purpose of developing fragility curves, a number of 30 natural g.m. records are selected from the European database [38]. These records are chosen in a range of magnitude and source to site distance of 5.5-7.0 and 25-75 km respectively and they are compatible with the type 1 uniform hazard spectrum given in Eurocode 8 [34], with soil type D $(S=1.35)$ and peak ground acceleration $a_{g}=0.1 \mathrm{Sg}$ (Figure 8). This acceleration value corresponds, on average, to the first frame yielding and permits to limit excessive scaling of the records [39].

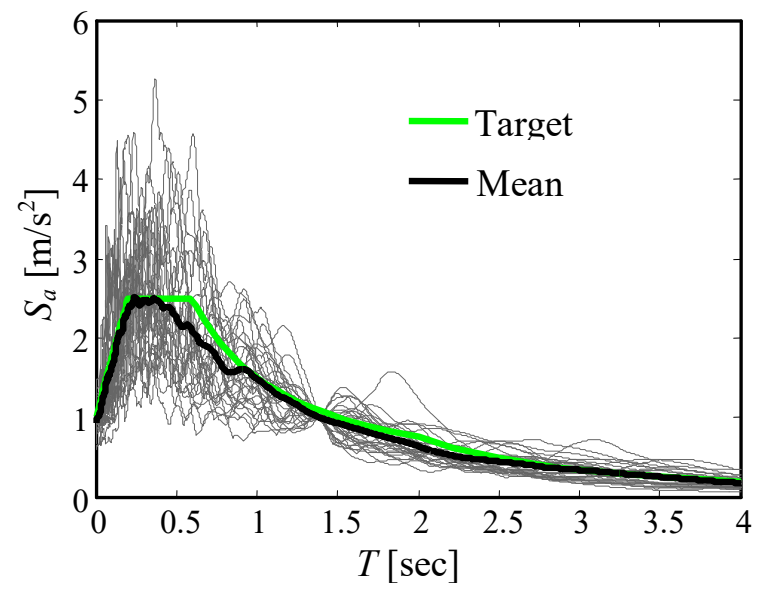

Figure 8. Code input spectrum, records spectra, and mean spectrum of records. 
In order to perform IDAs, the records are scaled to the same value of the spectral acceleration at the fundamental vibration period of the system $S_{a}(T)$. It is noteworthy that the vibration period, and consequently the $I M$, are different for the bare and the retrofitted frames and vary with $\alpha$. Thus, the g.m. records are re-scaled for each value of $\alpha$ according to the $I M$ of the considered system. Figure 8 shows the code input spectrum, the spectra of the scaled records and the corresponding mean spectrum, for the case of the bare frame.

The dynamic analyses have been carried out on the numerical model developed in OpenSees [28] and described in section 3. For each record, for each $I M$ value and for each element of the frame, the maximum-over-time values of the EDPs listed in section 2 have been recorded. The maximum-over-time values of the tension $\left(\sigma_{t}\right)$ and compression $\left(\sigma_{c}\right)$ stresses at each joints of the frame have been calculated through the following formulas $[40,41]$ :

$$
\sigma_{t, c}=\frac{N_{c}}{2 A_{c}} \mp \sqrt{\left(\frac{N_{c}}{2 A_{c}}\right)^{2}+\left(\frac{V_{j}}{b_{j} \cdot h_{j}}\right)^{2}}
$$

where $V_{j}$ is the joint shear and $b_{j}$ and $h_{j}$ are respectively the base and height of the joint resisting shear area. The joint shear is evaluated as:

$$
V_{j}=\frac{M_{l}}{z_{l}}+\frac{M_{r}}{z_{r}}-V_{c}
$$

where $M$ and $z$ are respectively the moments and the internal lever arms, subscript $l$ and $r$ indicate respectively the left and right beams adjacent to the joint, and $V_{c}$ is the column shear. Coherently with the capacity limits assumed in the retrofit design procedure, the limits of the concrete and steel capacity are set equal to $\varepsilon_{c u}=0.0035$ and $\varepsilon_{s u}=0.04$ [34]. The RC elements shear resistance $V_{u}$ is evaluated according to the formulas proposed by [42]:

$$
V_{s u}=V_{c}+V_{s}+V_{n}
$$

where account is made of the contribution of concrete $\left(V_{c}\right)$, shear reinforcements $\left(V_{s}\right)$, and normal force $\left(V_{n}\right)$. These contributions can be evaluated by the following equations [42]:

$$
V_{c}=0.8 A_{c} K \sqrt{f_{c}} \quad ; \quad V_{s}=A_{h} f_{y h} \frac{D-c}{s} \cot 30^{\circ} ; V_{n}=N_{c} \tan \gamma
$$

where $f_{c}$ and $f_{y h}$ are respectively the compressive strength of concrete and the yielding strength of transverse reinforcements. $A_{c}$ is the gross section of the column while $A_{h}$ is the total area of transverse reinforcement. The coefficient 0.8 takes into account of the effective shear area. $D$ and $c$ are the section depth and the neutral axis depth, $s$ is the stirrup spacing, $N_{c}$ is the axial force and $\gamma$ is the angle between the vertical and the line connecting the compressive centre at the top and at the bottom of the section column. Factor $K$ assumes values in the range 0.29 to 0.1 depending on the member displacement ductility demand. The shear resistance of beams is calculated by assuming a zero axial force and by considering the contribution of concrete and shear reinforcements only.

Finally, the resistance in tension and in compression of beam-column-joints is evaluated according to $[40,41]$ respectively, where the following capacity limits are suggested:

$$
\sigma_{t}<0.42 \sqrt{f_{c}} ; \sigma_{c}<0.5 f_{c} \quad\left(f_{c} \text { in } \mathrm{MPa}\right)
$$


Figures 9 and 10 report the results of multi-record IDA, expressed in terms of variation with $I M$ of the monitored EDP samples.
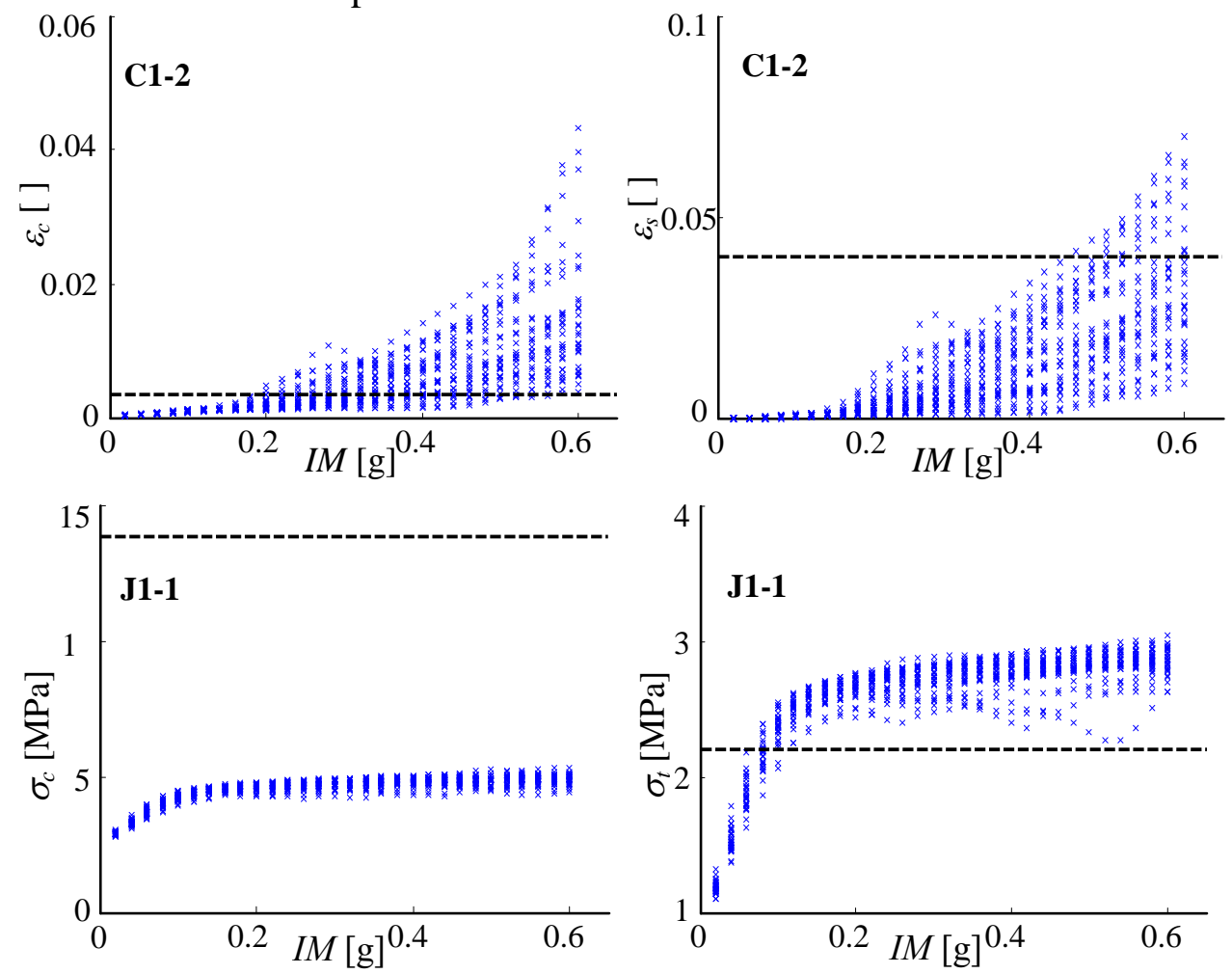

Figure 9. Demand samples and corresponding capacity limits for the case of bare frame.
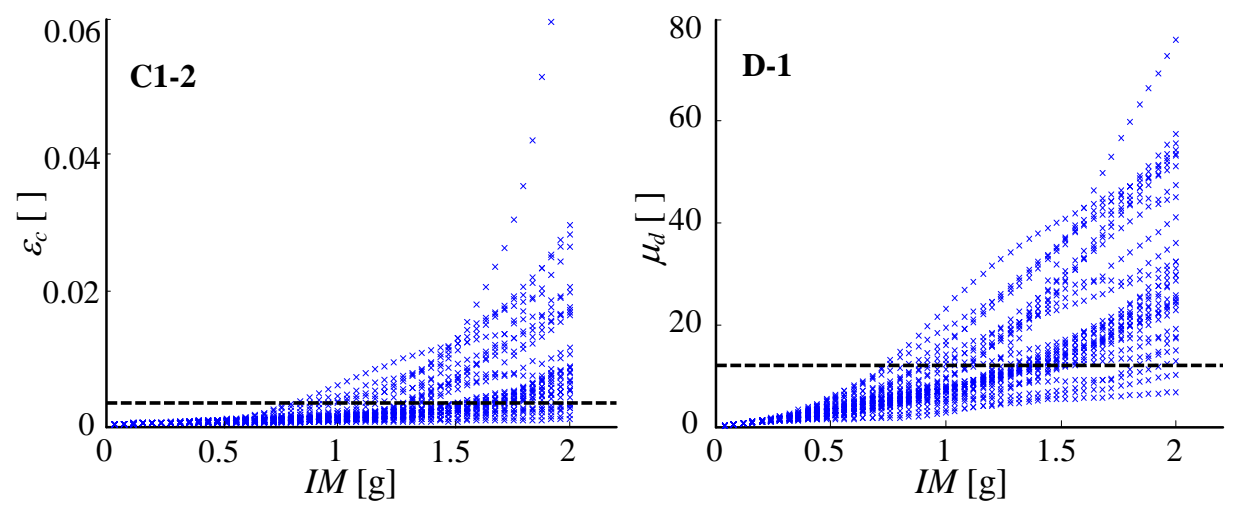

Figure 10. Demand samples and corresponding capacity limits for $\alpha=1.6$.

In Figure 9, the samples of the maximum-over-time values of the concrete compressive strain $\varepsilon_{c}$ and steel strain $\varepsilon_{s}$ at the most critical section of C1-2 column are illustrated, for the case of the bare frame. The corresponding capacity limits are also reported. It is observed in both cases that the dispersion of the demand increases for increasing $I M$. In the same figure, the values of $\sigma_{c}$ and $\sigma_{t}$ recorded at joint J1-1 are also reported and compared with the corresponding capacity limits. It is observed that the dispersion of these EDPs is quite constant for increasing values of the $I M$. This aspect is typical of such a system with non linear behaviour, in which the plasticization of the members limits the stresses in the joints, and the shear in the members themselves. It is noteworthy that, if conversely the demand were evaluated in terms of displacements or deformations rather on stresses or forces, the 
dispersion would increase for increasing $I M$. Figures 10 plots the values of $\varepsilon_{c}$ at column C1-2 and the maximum-over-time value of the ductility $\mu_{d}$ experienced by dissipative brace D-1 at the base storey, for the case of retrofitted frame with retrofit level $\alpha=1.6$. The dissipative brace and the column are characterized by large dispersion of the demand for large $I M$ values. The component fragility curves are evaluated for each limit state and for each frame member by comparing the demand samples with the corresponding capacity limits. Then, the system fragility curves are derived by assuming a series arrangement of the component fragilities. Figure 11a reports the lognormal component fragility curves for the case of the bare frame. It is observed that joint failure in tension is the most critical limit state. However, this limit state provides only a measure of the damage of the joints due to the concrete degradation and it is not deemed as critical as the brittle failure of the joint in compression, as observed in [40]. For this reason, it is disregarded in developing the system fragility curve. Therefore, concrete crushing in compression (LS1) is the most critical failure modality, while steel rupture (LS2) is much less probable and failure of joints in compression and shear failure have a zero probability of occurrence. Figure $11 \mathrm{~b}$ reports the numerical system fragility curve, coinciding with the fragility curve corresponding to concrete failure (LS1). In the same figure, the comparison between the numerical system fragility curve and its lognormal approximation demonstrates the accuracy of the fitting. Since similar satisfactory results in terms of fitting have been obtained for all the fragility curves developed in the study, only analytical curves will be reported in the following.

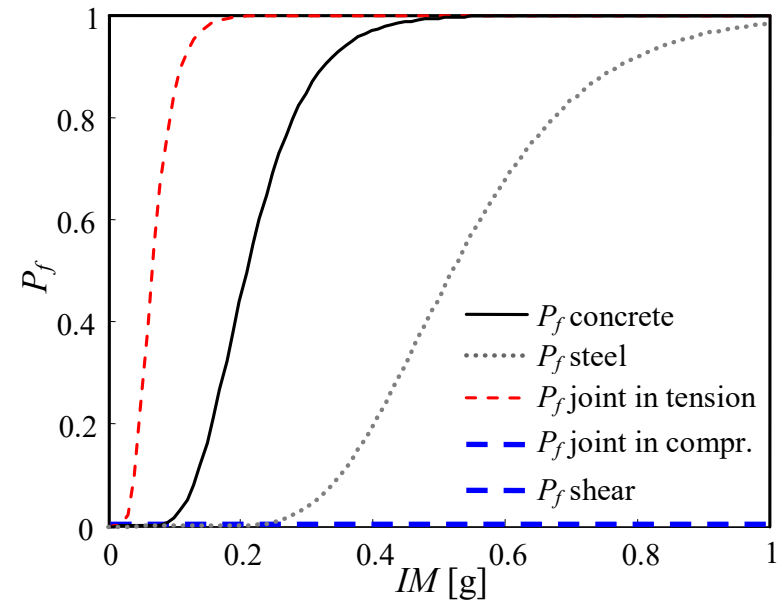

(a)

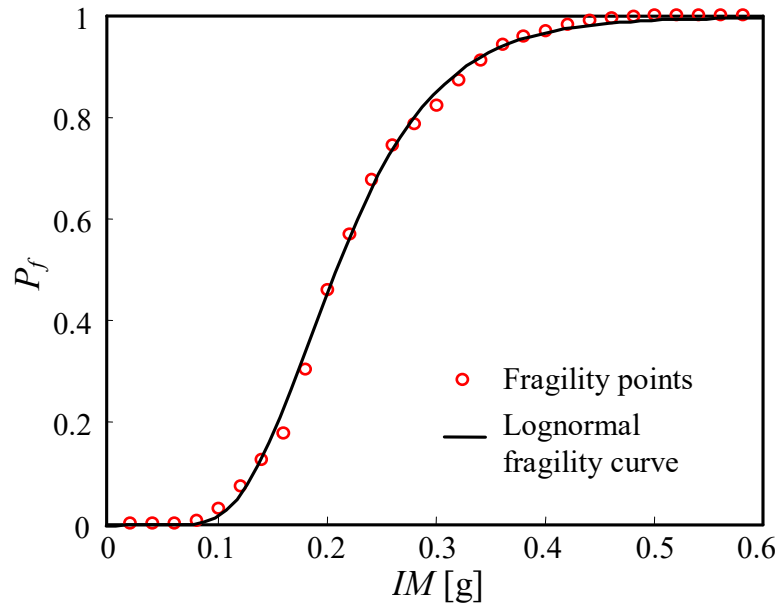

(b)

Figure 11. a) Lognormal fragility curves for the different failure modes and b) system numerical and lognormal fragility curve.

Figure 12 shows the fragility curve of the most vulnerable elements and of the system, for the bare frame (Figure 12a) and for the three retrofitting levels corresponding to $\alpha=0.4, \alpha=1.6$ and $\alpha=3.2$ (Figure 12b). In Figure 12a it is observed that the most vulnerable components of the bare frame are column C1-2 and column C1-3, failing in concrete crushing mode (LS1) and exhibiting a similar vulnerability. It is noted that this results is consistent with the results of pushover analysis (Figure 7b). In Figure 12b it is observed that for low values of $\alpha(\alpha=0.4)$ the vulnerabilities of the two columns remain comparable to each others, and also similar to the vulnerability of the most critical dissipative brace (D-1). This confirms the reliability of the simplified design procedure, which has the two main aims of avoiding drastic changes to 
the internal action distribution in the frame and of achieving a simultaneous failure of both the frame and the braces. Also in the case corresponding to $\alpha=1.6$, the fragility curves of the most critical frame components and of the most critical dissipative brace are very close. However, column $\mathrm{C} 1-2$ is more vulnerable than column $\mathrm{C} 1-3$. This can be attributed to the bracing system configuration (Figure 2), which induces a higher level of axial load on column $\mathrm{C} 1-2$ with respect to column $\mathrm{C} 1-3$. The trend is confirmed by the results of the case corresponding to $\alpha=3.2$, where the fragility curve of column C1-2 differs significantly from the others and tends to coincide with the system fragility curve. This means that system failure is mainly due to $\mathrm{C} 1-2$ column failure, as consequence of the excessive axial force transmitted by the bracing system on this column. As it will be shown later in the paper, this phenomenon, which is not considered in the application of the simplified procedure for the braces design, induces a significant reduction of the retrofit effectiveness for high $\alpha$ values

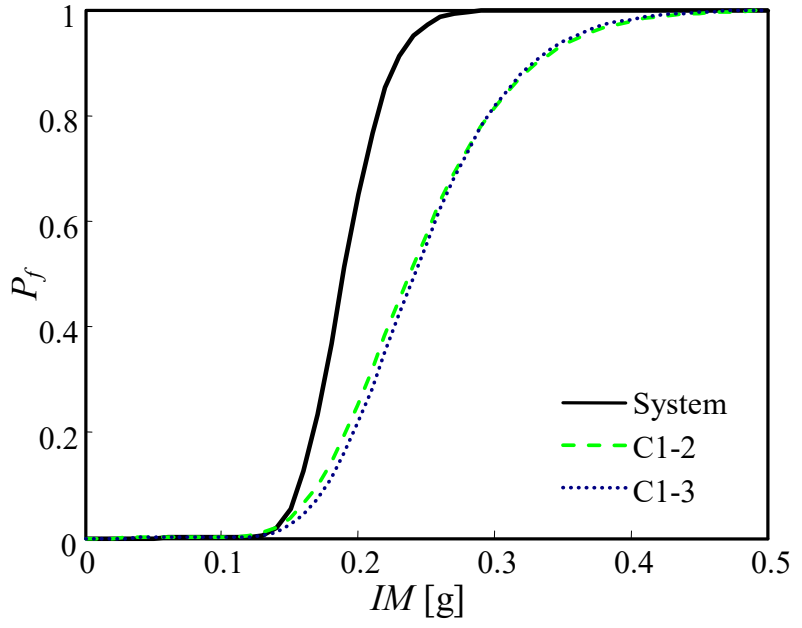

(a)

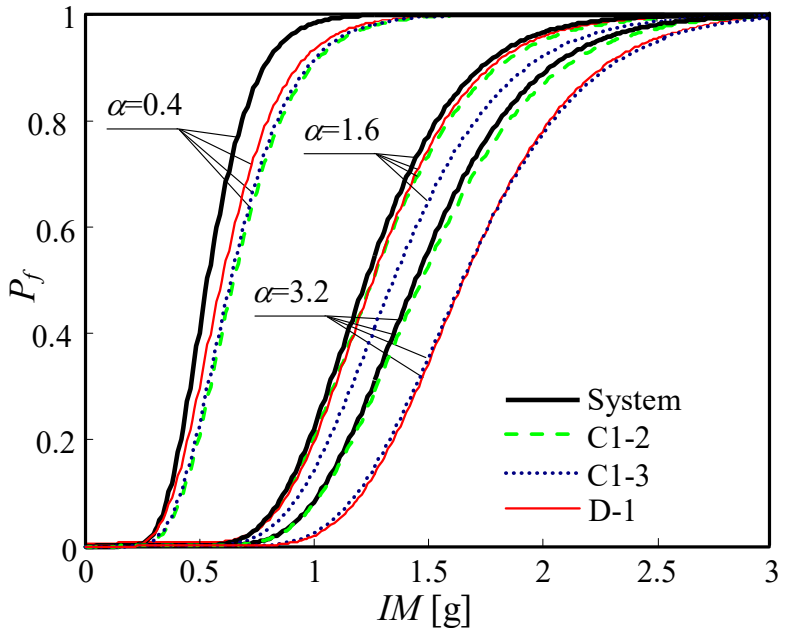

(b)

Figure 12. Fragility curve of the system and of the most vulnerable components for a) bare frame and $b$ ) frame retrofitted for selected retrofit levels.

Another important consideration which deserves to be pointed out concerns the BRBs behaviour at the different stories. In Figure 13a, the fragility curves of the BRBs at the first (D-1), second (D-2) and third (D-3) storey are reported, for the case corresponding to $\alpha=0.4$. The vulnerabilities of the three BRBs are comparable, i.e., for a same $I M$ value, the BRBs have a similar probability of attaining their maximum ductility capacity. Differently, in the case corresponding to $\alpha=1.6$, the fragility curves of the three BRBs (Figure 13b) differ significantly from each other. In fact, for the explored values of the $I M$ (up to $3 \mathrm{~g}$ ), the probability of failure of dissipative brace D-3 is significantly smaller than the probability of failure of dissipative brace D-2 and D-1. This can be explained recalling that BRBs show a very low post-yielding stiffness and thus the frame with BRBs has a significant tendency to soft-storey mechanism formation. This tendency, which is amplified if the capacity-todemand ratio of BRBs is not well balanced along the storey levels, can be reduced only by a system acting in parallel with the BRBs and able to redistribute the plastic deformation along the storey levels [43]. In this case, the RC existing frame, due to its hardening behaviour, is able of redistributing the plastic deformations along the storey levels. However, for increasing value of $\alpha$ this capability tends to decrease, and consequently the localization of 
plastic deformation at selected storey levels becomes more relevant and results in different BRBs vulnerabilities. This trend is also confirmed by the results of the case corresponding to $\alpha=3.2$, where it is noted that the fragility curve of brace D-1 is significantly higher than the fragility curves of the braces D-2 and D-3.

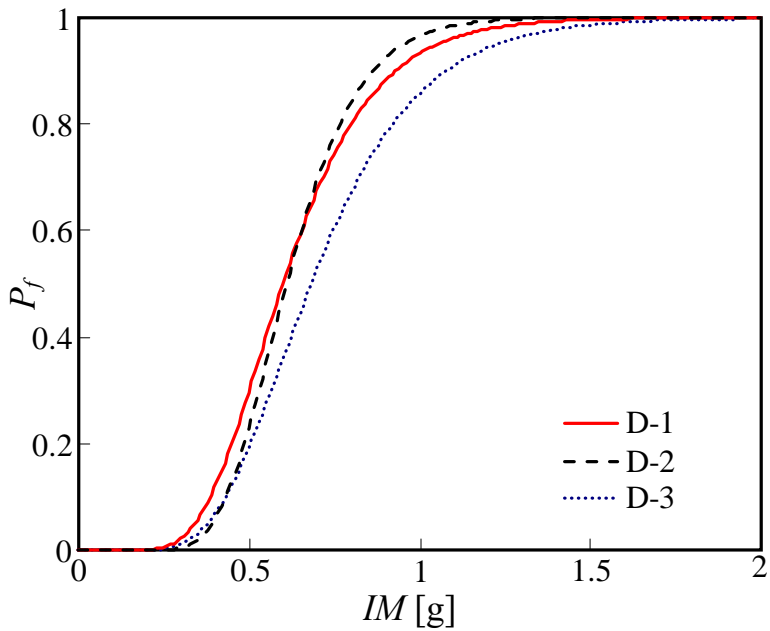

(a)

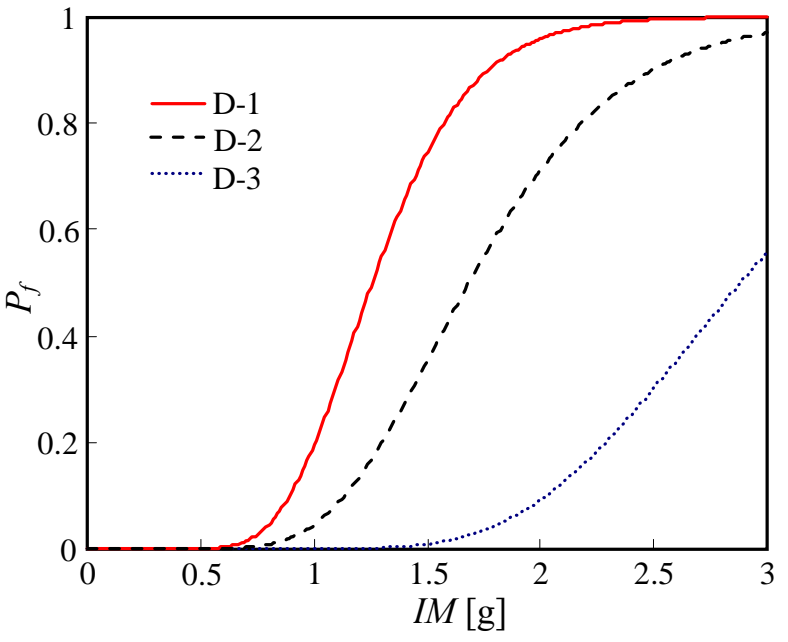

(b)

Figure 13. Fragility curves of the BRBs at the different storey levels for a) the case with $\alpha=0.4 \mathrm{~b}$ ) the case with $\alpha=1.6$.

Figure 14a compares the system fragility curves for all the retrofit levels considered, including the bare frame case.

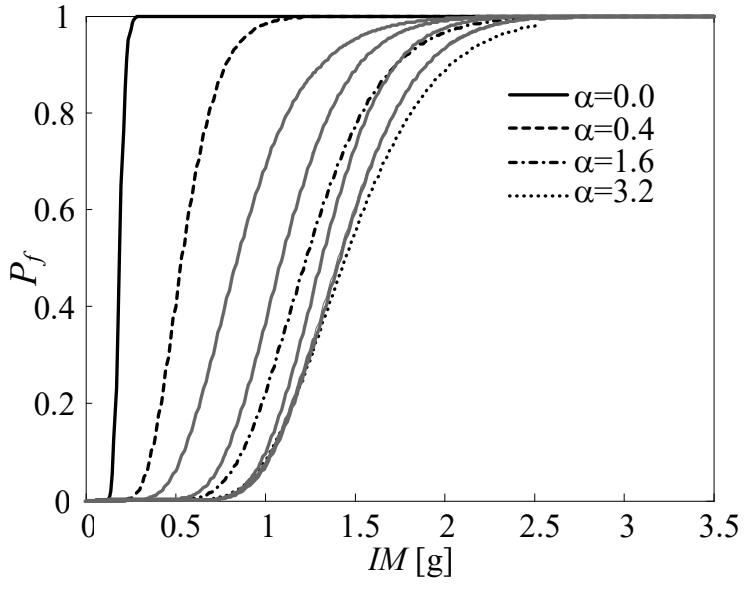

(a)

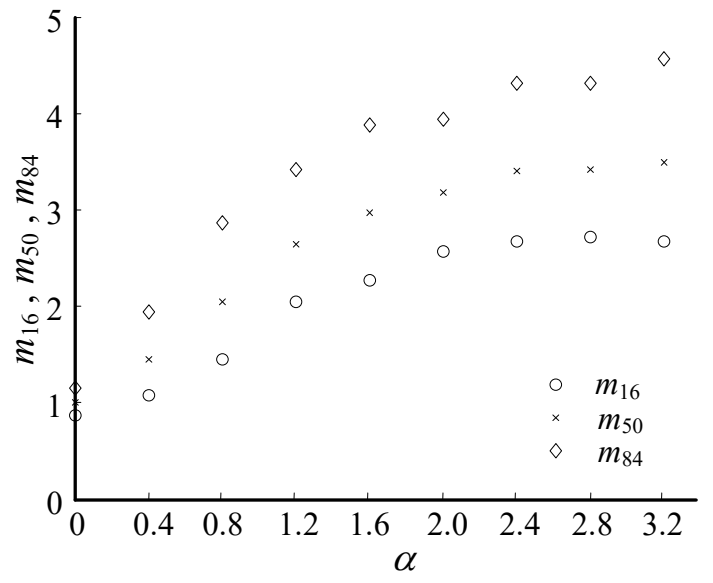

(b)

Figure 14. a) System fragility curves for the bare frame and for the retrofitted frame, and b) variation with $\alpha$ of the factors $m_{50}, m_{84}$ and $m_{16}$.

Parameter $I M_{c, 50}$ increases for increasing values of $\alpha$, as expected. However, as already stressed previously, this parameter does not directly provide information about the effectiveness of the retrofit, since the natural periods of the systems are different. Figure $14 \mathrm{~b}$ reports the factors $m_{50}, m_{84}$, and $m_{16}$, which have been defined in section 2 in order to compare the retrofit effectiveness when a structural dependent $I M$, such as the spectral acceleration $S_{a}(T)$ at the fundamental period of the structure, is used. It is observed that for 
values of $\alpha$ up to 1.6 , the capacity margin ratio increases about linearly with $\alpha$, while for higher values this relation becomes strongly non linear. This implies that the effectiveness of the retrofit increases weakly for values of $\alpha$ larger than 1.6, in consequence of the premature failure of column C1-2 mainly due to the high axial forces induced by the braces (as shown in Figure 12b).

Figure 15a plots the dispersion measure $\beta_{c}$ evaluated according to Equation (1) for increasing values of $\alpha$ and shows that a significant increase of the dispersion occurs when elasto-plastic braces are introduced into the bare frame. This is consequence of the increase of the number of the vulnerable components (frame members and dissipative braces) and of the more pronounced nonlinear behaviour induced by the introduction of BRBs. As already discussed, the more pronounced non linear behaviour adds dispersion to the response, when this latter is evaluated in terms of displacements or deformations. Accounting for this increase of dispersion is important due to its influence on the estimate of the seismic risk [17].

Finally, in order to quantify the differences in the retrofit effectiveness evaluation when local and global EDPs are used, system fragility curves are evaluated also by considering global EDPs, such as the maximum interstorey drift (IDR) and the top storey drift (TSD). Figure $15 \mathrm{~b}$ reports the comparison between the values of previously defined parameter $m_{50}$ and the values of parameters $m_{50, \mathrm{IDR}}$ and $m_{50, \mathrm{TSD}}$ evaluated on the basis of the fragility curves developed by considering the IDR and the TSD respectively.

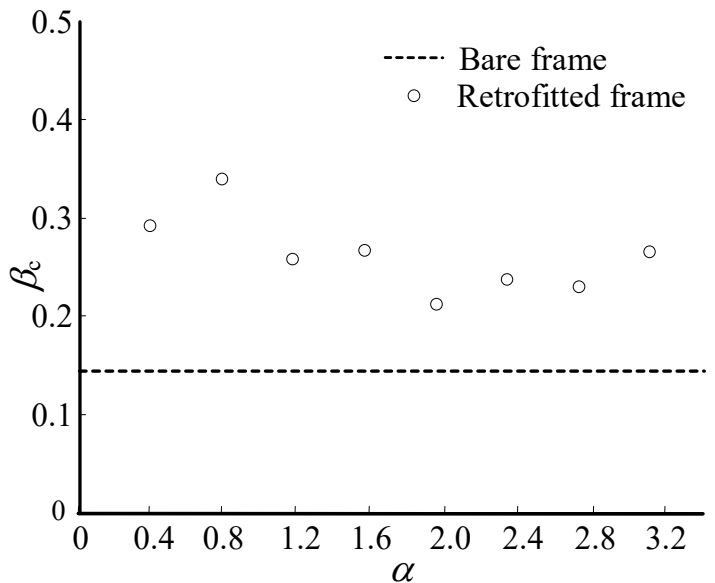

(a)

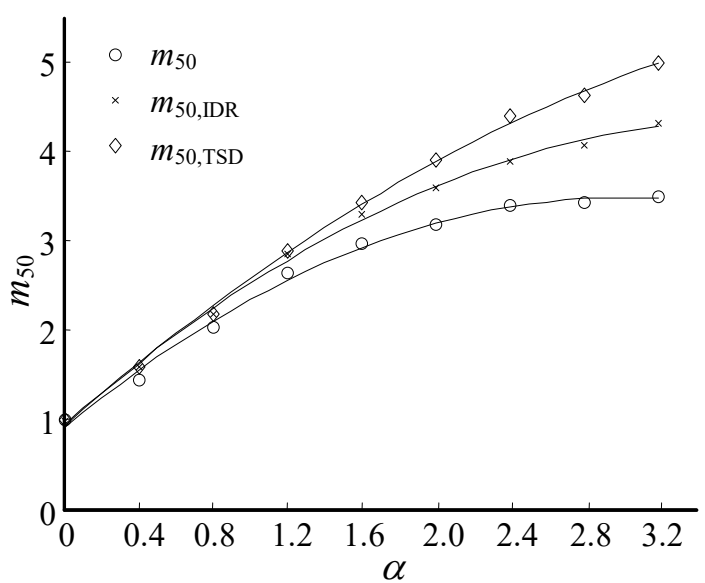

(b)

Figure 15. Variation with $\alpha$ of a) dispersion measure $\beta_{c}$ and b) factor $m_{50}$ corresponding to the use of different local and global EDPs.

In order to make this comparison, the global EDPs limits $\mathrm{IDR}_{\mathrm{u}}$ and $\mathrm{TSD}_{\mathrm{u}}$ are chosen so that

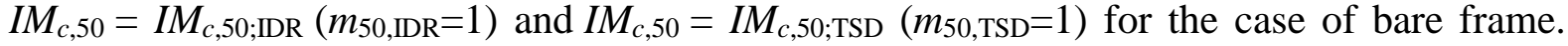
The limits obtained are $\mathrm{IDR}_{\mathrm{u}}=1.302 \%$ and $\mathrm{TSD}_{\mathrm{u}}=1.029 \%$. It is evident from Figure $15 \mathrm{~b}$ that the use of global EDPs instead of more accurate local EDPs results in a significant overestimation of the seismic increment capacity of the retrofitted frames, especially for large $\alpha$ values. In fact, as already discussed in the introduction, local phenomena such as the increment of axial force in the columns adjacent to the dissipative braces are not accounted for by these global EDPs. This confirms that local EDPs must be adopted to accurately estimate the effectiveness of the retrofit based on dissipative braces. Otherwise, if global EDPs are considered, proper limits need to be estimated for each retrofit level. 


\section{CONCLUSIONS}

The paper illustrates a probabilistic methodology for assessing the vulnerability of RC buildings with limited ductility capacity and the effectiveness of the retrofit by means of dissipative braces. The methodology is based on the development of fragility curves of the bare and the retrofitted frames. It employs an efficient structure-dependent intensity measure (IM) and involves performing multi-record non linear incremental dynamic analysis to account for the randomness of the earthquake excitation. Local EDPs are used to capture the modifications of the frame response induced by the introduction of the bracing system. Numerical fragility curves are derived by comparing the samples of the demand with the corresponding capacity limits. The component fragility curves are built for each single structural component and for each single limit state considered. The system fragility curves are derived by assuming a series arrangement of the component limit states. Finally, proper synthetic parameters describing the system fragility curves are introduced in order to accurately compute the increment in the safety achieved by the retrofit while employing a structure dependent $I M$, such as the spectral intensity at the natural period of the structure.

The capability and effectiveness of the proposed methodology is tested by considering a realistic benchmark RC frame with limited ductility capacity retrofitted by elasto-plastic braces. The braces are designed by applying a widespread method based on an equivalent nonlinear SDOF approximation and by considering different values of the shear capacity of the bracing system.

On the basis of the analysis of the results, the following conclusions can be drawn. The comparison of the single components fragility curves permits to individuate the most vulnerable elements of the frame that may change by increasing the retrofit level. In the case study considered, these elements coincide with the two columns involved in the bracing system, failing in concrete crushing mode. However, for low retrofit levels, the fragility curves of these columns are very similar to each other and they are also similar to the fragility curve of the most critical dissipative brace, whereas for large retrofit levels the fragility curve of the most compressed column significantly differs from the other fragility curves and tends to coincide with the system fragility curves. This is a consequence of the very different axial load induced in the columns by the braces action in the case of high retrofit level. Moreover, by comparing the fragility curves of the BRBs at different storey levels, the differences among the BRB vulnerabilities can be evaluated. For low retrofit levels, the BRBs exhibit similar vulnerabilities, since the bare frame is able to redistribute the plastic deformations along the different storey levels. Conversely, for large retrofit levels this capability decreases and the BRB vulnerabilities differ significantly one from the other.

In order to compute accurately the increment of capacity due to retrofit for increasing values of $\alpha$ (retrofit levels) while using a structure-dependent $I M$, parameter $m_{50}$ is introduced. The values assumed by $m_{50}$ for all the retrofit cases considered demonstrate that the effectiveness of the retrofit system increases only weakly for high retrofit levels in consequence of the previously described variations in the component vulnerability. Moreover, the response dispersion, evaluated by means of parameter $\beta_{c}$, significantly increases when elasto-plastic braces are introduced into the bare frame. This result is important since the seismic risk estimate is strongly affected by the dispersion of the system response.

Finally, the capacity margin ratio evaluated by using local EDPs for monitoring the system response is compared with the capacity margin ratios evaluated by monitoring the response through global EDPs such as the maximum interstorey drift and the top storey drift. The 
results obtained show that the use of these global EDPs results in a significant overestimation of the seismic increment capacity due to dissipative braces action, especially for large retrofit levels. Thus, it is concluded that the accurate estimation of the effectiveness of the retrofit by means of dissipative braces should be carried out by employing local EDPs capable of accounting for local phenomena. Alternatively, if global EDPs are used, it is recommended to calibrate different capacity limits for each retrofit level considered.

\section{REFERENCES}

1. Soong TT, Spencer BF. Supplemental energy dissipation: state-of-the-art and state-of-thepractice. Engineering Structures 2002; 24(3):243-259. DOI:10.1016/S01410296(01)00092-X.

2. Christopoulos C, Filiatrault A. Principles of passive supplemental damping and seismic isolation. IUSS Press: Pavia, Italy, 2006.

3. Hueste MD, Bai JW. Seismic Retrofit of a Reinforced Concrete Flat-Slab Structure: Part II - Seismic Fragility Analysis. Engineering Structures 2006; 29(6):1178-1188. DOI:10.1016/j.engstruct.2006.07.022

4. Ramamoorthy S, Gardoni P, Bracci J. Probabilistic Demand Models and Fragility Curves for Reinforced Concrete Frames. Journal of Structural Engineering 2006; 132(10):15631572. DOI:10.1061/(ASCE)0733-9445(2006)132:10(1563)

5. Güneyisi EM, Altay G. Seismic fragility assessment of effectiveness of viscous dampers in R/C buildings under scenario earthquakes. Structural Safety 2008; 30(5):461-480. DOI:10.1016/j.strusafe.2007.06.001

6. Özel AE, Güneyisi EM. Effects of eccentric steel bracing systems on seismic fragility curves of mid-rise r/c buildings: a case study. Structural Safety 2011; 33(1):82-95. DOI:10.1016/j.strusafe.2010.09.001

7. Guneyisi EM. Seismic reliability of steel moment resisting framed buildings retrofitted with buckling restrained braces. Earthquake Engineering and Structural Dynamics 2011. DOI: 10.1002/eqe.1161

8. Lupoi G, Lupoi A, Pinto PE. Seismic risk assessment of rc structures with the "2000 SAC/FEMA" method. Journal of Earthquake Engineering 2002; 6(4): 499-512. DOI:10.1080/13632460209350427

9. Mackie K, Stojadinovic B. Seismic demands for performance-based design of bridges. PEER Report 2003/16.

10. Lee TH, Mosalam KM. Seismic demand sensitivity of reinforced concrete shear-wall building using FOSM method. Earthquake Engineering and Structural Dynamics 2005; 34(14):1719-1736. DOI:10.1002/eqe.506

11. Tubaldi E, Barbato M, Dall'Asta A. Influence of model parameter uncertainty on seismic transverse response and vulnerability of steel-concrete composite bridges with dual load path. Journal of Structural Engineering 2012. DOI:10.1061/(ASCE)ST.1943541X.0000456

12. Padgett JE, Des Roches R. Methodology for the development of analytical fragility curves for retrofitted bridges. Earthquake Engineering and Structural Dynamics 2008; 37(8):1157-1174. DOI:10.1002/eqe.8012008

13. Porter KA, Kiremidjian AS, Le Grue JS. Assembly-based vulnerability of buildings and its use in performance evaluation. Earthquake Spectra 2001; 17(2):291-312. DOI:10.1193/1.1586176 
14. Ghosh J, Padgett JE. Probabilistic seismic loss assessment of against bridges using a component level cost estimation approach. Earthquake Engineering and Structural Dynamics 2011; 40(15):1743-1761. DOI:10.1002/eqe.1114

15. Katsanos EI, Sextos AG, Manolis GD. Selection of earthquake ground motion records: A state-of-the-art review from a structural engineering perspective. Soil Dynamics and Earthquake Engineering 2009; 30(4):157-169. DOI:10.1016/j.soildyn.2009.10.005

16. Liel AB, Haselton CB, Deierlein GG. Seismic Collapse Safety of Reinforced Concrete Buildings: II. Comparative Assessment of Non-Ductile and Ductile Moment Frames, Journal of Structural Engineering 2011; 137(4):492-502. DOI: 10.1061/(ASCE)ST.1943-541X.0000275

17. Bradley BA, Dhakal RP. Error estimation of closed-form solution for annual rate of structural collapse Earthquake Engineering and Structural Dynamics 2008; 37(15):17211737. DOI: $10.1002 /$ eqe. 833

18. Kasai K, Fu Y, Watanabe A. Passive control systems for seismic damage mitigation. Journal of Structural Engineering 1998; 124(5):501-512.

19. Kwon OS, Elnashai A. The effect of material and ground motion uncertainty on the seismic vulnerability curves of RC structure. Engineering Structures 2006; 28(2):289-303. DOI:10.1016/j.engstruct.2005.07.010

20. Vamvatsikos D, Cornell CA. Incremental dynamic analysis. Earthquake Engineering and Structural Dynamics 2002; 31(3):491-514. DOI: 10.1002/eqe.141

21. Luco N, Cornell CA. Structure-Specific Scalar Intensity Measures for Near-Source and Ordinary Earthquake Ground Motions. Earthquake Spectra 2007; 23(2):357-392. DOI: $10.1193 / 1.2723158$

22. Cornell CA, Fatemeh J, Hamburger RO, Foutch DA. Probabilistic Basis for 2000 SAC Federal Emergency Management Agency Steel Moment Frame Guidelines. Journal of Structural Engineering 2002; 128(4):526-533. DOI: 10.1061/(ASCE)07339445(2002)128:4(526)

23. Alam MS, Nehdi M, Youssef MA. Seismic performance of concrete frame structures reinforced with superelastic shape memory alloys. Smart Structures and Systems 2009; 5(5):565-585.

24. Bracci JM, Reinhorn AM, Mander JB. Seismic resistance of reinforced concrete frame structures designed only for gravity loads: part I-design and properties of a one-third scale model structure. Technical report NCEER-92-0027, NCEER, Buffalo, New York, USA, 1992.

25. Aycardi LE, Mander JB, Reinhorn AM. Seismic resistance of reinforced concrete frame structures designed only for gravity loads: experimental performance of subassemblages. ACI Structural Journal 1994; 91(5):552-563.

26. Bracci JM, Reinhorn AM, Mander JB. Seismic resistance of reinforced concrete frame structures designed for gravity loads: performance of structural system. ACI Structural Journal 1995; 92(5):597-608.

27. ACI Committee 318. Building Code Requirements for Reinforced Concrete and Commentary (ACI 318-89/ACI 318R-89), American Concrete Institute, Detroit, 1989.

28. McKenna F, Fenves GL, Scott MH. OpenSees: Open system for earthquake engineering simulation. Pacific Earthquake Engineering Center, University of California, Berkeley, CA, 2006.

29. Scott MH, Fenves GL. Plastic hinge integration methods for force-based beam- 
column elements. Journal of Structural Engineering 2006; 132(2):244-252. DOI: 10.1061/(ASCE)0733-9445(2006)132:2(244)

30. Panagiotakos TB, Fardis MN. Deformation of reinforced concrete members at yielding and ultimate. ACI Structural Journal 2001; 98(2):135-148.

31. Di Sarno L, Manfredi G. Seismic retrofitting with buckling restrained braces: Application to an existing non-ductile RC framed building. Soil Dynamics and Earthquake Engineering 2010; 30(11):1279-1297. DOI:10.1016/j.soildyn.2010.06.001

32. Dall'Asta A, Ragni L, Tubaldi E, Freddi F. Design methods for existing RC frames equipped with elasto-plastic or viscoelastic dissipative braces. Proceedings of XIII Convegno Nazionale ANIDIS, Bologna, Italy, 2009.

33. Ragni L, Zona A, Dall'Asta A. Analytical expressions for preliminary design of dissipative bracing systems in steel frames. Journal of Constructional Steel Research 2011; 67(1):102-113. DOI: 10.1016/j.jcsr.2010.07.006

34. European Committee for Standardization (ECS). Eurocode 8 - Design of structures for earthquake resistance, EN1998, Brussels, 2005.

35. Antonucci R, Balducci $\mathrm{F}$, Castellano $\mathrm{MG}$, Donà $\mathrm{F}$. Pre-casted RC buildings with buckling restrained braces: the example of the new building of the faculty of engineering in Ancona. Proceedings of 2nd International FIB Congress, Napoli, 2006.

36. Uang CM, Nakashima M. Steel Buckling-Restrained Braced Frames. In: Bozorgnia Y, Bertero VV (eds.) Earthquake Engineering: From Engineering Seismology to Performance-Based Engineering. CRC Press: Boca Raton, FL, 2004.

37. Zona A, Dall'Asta A. Elastoplastic model for steel buckling-restrained braces. Journal of Constructional Steel Research 2012; 68(1):118-125. DOI: 10.1016/j.jcsr.2011.07.017

38. Ambraseys N, Smith P, Berardi R, Rinaldis D, Cotton F, Berge-Thierry C. Dissemination of European Strong-Motion Data. CD-ROM Collection. European Council, Environment and Climate Research Programme, 2000.

39. Pinto P E, Giannini R, Franchin P. Seismic Reliability Analysis of Structures. IUSS Press: Pavia, Italy, 2004.

40. Priestley MJN, Seible F, Calvi GM. Seismic Design and Retrofit of Bridges. Wiley: New York, US, 1995.

41. Priestley MJN. Displacement-based seismic assessment of reinforced concrete buildings. Journal of Earthquake Engineering 1997; 1(1):157 -192.

42. Priestley M J N, Verma R, Xiao Y. Seismic shear strength of reinforced concrete columns. Journal of Structural Engineering 1994; 120(8):2310-2329. DOI: 10.1061/(ASCE)0733-9445(1994)120:8(2310)

43. Zona A, Ragni L, Dall'Asta A. Sensitivity-based study of the influence of brace overstrength distributions on the seismic response of steel frames with BRBs. Engineering Structures 2012; 37(1):179-192. DOI: 10.1016/j.engstruct.2011.12.026 